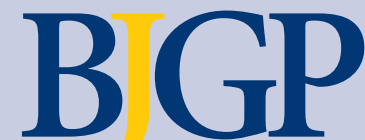

EDITOR

Roger Jones, DM, FRCP, FRCGP, FMedSci London

DEPUTY EDITOR

Alec Logan, FRCGP

Motherwell

JOURNAL MANAGER

Catharine Hull

SENIOR ASSISTANT EDITOR

Erika Niesner

ASSISTANT EDITOR

Moira Davies-Cinar

EDITORIAL ASSISTANT

Tania Marszalek

ADVERTISING EXECUTIVE

Brenda Laurent

EDITORIAL BOARD

Richard Baker, MD, FRCGP

Leicester

Stephen Barclay, MD, FRCGP, DRCOG

Cambridge

Chris Butler, MD, MRCGP

Cardiff

Kath Checkland, PhD, MRCGP

Manchester

Mark Gabbay, MD, FRCGP

Liverpool

Clare Gerada, MBE, FRCGP, MRCPsych

London

Murray Lough, MD, FRCGP

Glasgow

David Mant, MD, FRCGP, FMedSci

Oxford

Tim Peters, MSc, PhD, CStat, FFPH

Bristol

Chris Salisbury, MD, FRCGP

Bristol

John Sandars, MSc, MD, FRCGP, MRCP

Leeds

Mark Shapley, FRCGP, DCH, DRCOG

Newcastle-under-Lyme

Niroshan Siriwardena, MMedSci, PhD,

FRCGP

Lincoln

Theo Verheij, MD, PhD, MRCGP

Utrecht, The Netherlands

Sue Wilson, BA, PhD, PGA

Birmingham

2009 impact factor: 2.442

EDITORIAL OFFICE

1 Bow Churchyard, London, EC4M 9DQ

(Tel: 0203188 7400, Fax: 0203188 7401).

E-mail: journal@rcgp.org.uk

http://www.rcgp.org.uk/bjgp

PUBLISHED BY

The Royal College of General Practitioners,

1 Bow Churchyard, London, EC4M 9DQ.

Registered charity number 223106. The BJGP is published by the RCGP, but has complete

editorial independence. Opinions expressed in the BJGP should not be taken to represent the policy of the RCGP unless this is specifically stated.

No endorsement of any advertisement is implied or intended by the RCGP.

PRINTED IN GREAT BRITAIN BY

HPM Limited, Prime House, Park 2000, Heighington

Lane Business Park,

Newton Aycliffe, Co. Durham DL5 6AR.

Printed on $100 \%$ recycled paper

ISSN 0960-1643 (Print)

ISSN 1478-5242 (Online)

\title{
September Focus
}

\section{PATIENT SAFETY AND DIAGNOSTIC ACCURACY}

Three papers in this month's BJGP focus on making an accurate, timely diagnosis - of cancer, dementia, and schizophrenia, all serious problems which, if diagnosed at an early stage, may be amenable to interventions of various kinds. In the most recent edition of Tomorrow's Doctors' ${ }^{1}$ the General Medical Council brings patient safety to centre stage, although with more of an emphasis on preventing medical harm than on avoiding misdiagnosis.

Diagnostic errors - missed or delayed diagnosis - appear to be surprisingly common in both hospital and community medical practice, and a growing body of research is beginning to tease out the causes of error and, thereby, devise approaches to prevent it. ${ }^{2}$ Between 40000 and 80000 hospital deaths in the US are thought to result from errors in diagnosis, and post-mortem studies reveal an incorrect or missed diagnosis in $5 \%$ of cases. ${ }^{2}$ The frequency of diagnostic error in primary care is less well studied but it is clear that a number of individual and systemic factors contribute to misdiagnosis. These include deficiencies in history taking and the physical examination, clinicians' failure to think of the correct diagnosis, especially in atypical presentations and rare cases, failure to order appropriate investigations, to follow up abnormal test results, and to refer for further assessment. The relative contribution of these mistakes varies among studies, but all have face validity and all are potentially tractable.

Shapley and colleagues' study (page 681) and Barraclough's accompanying editorial (page 639) deal with triggers to action; the presentation of symptoms that, individually or in combination, mandate a test or a referral or some further diagnostic step. The need for further research in primary care to determine which symptoms, under which circumstances, and in which patient, represent red or amber flags for urgent evaluation is clearly articulated. The potential role of the electronic patient record and 'intelligent' primary care computer systems capable of synthesising demographic, historical and clinical information, and generating prompts during the consultation should not be overlooked.

The study by Ahmad and colleagues (page 666) on the early diagnosis of dementia introduces the clinical knowledge base, teaching, training, and clinical experience as variables likely to influence the propensity to think of a diagnosis, to make it with confidence and to have a positive view of the likely benefit of the patient in doing so.

Paradoxically the older doctors in this study, more likely to make a correct diagnosis, were also more pessimistic about the therapeutic opportunities for demented patients, emphasising the importance of continuing medical education in linking experience to evidence.

Simon and colleagues from Bern, Switzerland (page 660) report a pioneering approach to improving the early diagnosis of schizophrenia through 'sensitising' GPs to early schizophrenia diagnoses by mailing them a series of brief vignettes with short commentaries. This randomised study demonstrated a significant effect on GPs' knowledge of prodromal schizophrenia: reminiscent of the use of A5 flyers distributed by the British Heart Foundation which increased awareness of the role of antithrombotic therapy in ischaemic heart disease.

William Osler was credited with saying that if we listened to the patient we would be told the diagnosis. This assertion probably felt more accurate at the end of the 19th century than it does amid the technology of the 21st, but it is still a reminder of the importance of listening. Some of my most grateful patients were those for whom I had done almost nothing else. Our group of articles on the QOF relate largely to the post-diagnostic management of long-term conditions and, of course, most of the important diagnostic work - ruling out serious illness as well as identifying it - done by GPs is relatively unexamined and is certainly not performance related. Given the fundamental requirement for patient safety, the potential for fragmentation, and discontinuity of patient care in the future, and the competing pressures on time in the consultation, methods of examining the outcomes of consultations 'at the sharp end,' at practice and individual level are also required. Critical event analysis, random chart reviews, cancer diagnostic audits, and the like all have a central place in the assurance of quality and the maintenance of patient safety.

\section{Roger Jones}

Editor

1. General Medical Council. Tomorrow's doctors. London: GMC, 2009.

2. Newman-Toker DE, Pronovost PJ. Diagnostic errors - the next frontier for patient safety. JAMA 2009; 301(10): 1060-1062.

3. Kostopoulou O, Delaney BC, Munro CW. Diagnostic difficulty and error in primary care - a systematic review. Fam Pract 2008; 25(6): 400-413.

DOI: 10.3399/bjgp10X515296

(c) British Journal of General Practice 2010; 60: 633-712. 